Richard A. Beers MD, Peter B. Kane MD, Imad Nsouli MD, Dennis Krauss MD

\title{
Does a mid-lumbar block level provide adequate anaesthesia for transurethral prostatectomy?
}

\begin{abstract}
In this prospective, randomized study, 23 patients having spinal anaesthesia for transurethral prostatectomy (TURP) were evaluated for the adequacy of their block using. a visual analog pain score (VAPS). Each patient with a "standard" $\left(\geq T_{10}\right)$ block level $(n=5)$ or "intermediate" $\left(L_{l}\right.$ or $\left.T_{12}\right)$ block level $(n=$ 5) found the block adequate. Sixty-two percent (8/13) of patients with a "low" $\left(\leq L_{3}\right)$ block level found their block adequate. The VAPS was assessed every five minutes or whenever pain abruptly increased during TURP; an "inadequate block" was defined as a VAPS $\geq 5 / 10$ during prostatic resection. Intravesical pressure was monitored and kept $<15 \mathrm{mmHg}$ to distinguish between pain from bladder distension and from prostatic resection. "Low" block patients (LBP) who found their block inadequate $(n=5)$ received supplemental intrathecal local anaesthetic given through a spinal catheter. The subsequent $L_{l}$ block level was adequate for TURP. In LBP, who found their block adequate $(n=8)$, a higher $(P<0.01)$ VAPS was observed than in patients with a "standard" block level. However, $a$ smaller $(P<0.05)$ maximum percent decrease in diastolic blood pressure was found in LBPs, than in "intermediate" or "standard" block patients. It is concluded that a spinal block $\geq L_{l}$ is adequate during TURP when bladder pressure is monitored and kept low. Mid-lumbar block levels should be reserved for patients in whom the benefit of minimizing haemodynamic changes outweighs the risk of a "less complete" anaesthetic.
\end{abstract}

Au cours de cette étude prospective randomisée, l'efficacité de la rachianesthésie est évaluée sur une échelle visuelle analogique

\section{Key words}

ANAESTHETIC TECHNIQUES: spinal; SURGERY: urological, TURP.

From the Department of Anaesthesiology, University Hospital, Syracuse, NY, and Division of Urologic Surgery, Veterans Administration Medical Center, Syracuse, NY.

Address correspondence to: Dr. R. Beers, Department of Anaesthesiology, University Hospital, 750 E. Adams St., Syracuse, NY 13210.

Accepted for publication 31st May, 1994.
(EVA) chez 23 patients soumis à une résection transuréthrale de la prostate (RTUP). Chaque patient $(n=5)$ bloqué au niveau "standard " $\left(\geq T_{10}\right)$ ou " intermédiaire " $\left(L_{1}\right.$ ou $\left.T_{12}\right)$ a trouvé le bloc suffisant. Soixante-deux pourcent (8/13) des patients avec un niveau "bas" $\left(\leq L_{3}\right)$ ont trouvé le niveau suffisant. Le score d'EVA a été évalué aux cinq minutes à chacun des moments où la douleur a augmenté subitement pendant la RTUP; le bloc a été considéré comme insuffisant lorsque l'EVA $\geq 5 / 10$ pendant la résection. La pression intravésicale a été monitorée et maintenue $<15 \mathrm{mmHg}$ pour distinguer la douleur de la distension vésicale de celle de la résection prostatique. Les patients à niveau "bas" (PNB) qui ont trouvé le bloc insuffisant $(n=15)$ ont reçu un supplément d'anesthésique local par un cathéter intrarachidien. Le niveau à $L_{1}$ a été par la suite considéré comme suffisant pour la RTUP. Chez les PNB qui ont trouvé le bloc suffisant $(n=8)$, un EVA plus élevé $(P<0,01)$ a été rapporté que chez les patients avec un niveau "standard". Cependant, une plus petite baisse maximale $(P<0,05)$ de la pression artérielle diastolique a été constatée chez les PNB que chez les patients à bloc « standard " ou " intermédiaire ». En conclusion, un bloc rachidien $\geq L_{I}$ est adéquat pendant la RTUP en autant que la pression vésicale est gardée basse. Les niveaux mid-lombaires devraient être réservés aux patients chez qui le bénéfice d'atténuer les modifications hémodynamiques est supérieur au risque d'une anesthésie moins complète.

It is commonly taught that a subarachnoid sensory block extending to at least the tenth thoracic dermatome is necessary to provide adequate anaesthesia during transurethral prostatectomy (TURP). ${ }^{1}$ Many patients undergoing anaesthesia and surgery for TURP have compromised cardiac and/or pulmonary reserve. For these patients, limiting the distribution of the block may reduce its adverse haemodynamic and pulmonary effects.

Evans, ${ }^{2}$ in a prospective study of 350 patients, found that those given spinal or caudal and/or lumbar epidural blocks "where the upper level of the block reached the third lumbar segment" had "complete analgesia ... in 
all cases. " However, Evans did not control for many factors which may have influenced the adequacy rate at a given block level. The patient's perception of pain was not objectively measured during the procedure and no definition of "inadequate block" was provided.

This study determined whether a subarachnoid block to a mid-lumbar level $\left(L_{3}\right)$ provided adequate anaesthesia during TURP when bladder pressure is continuously monitored and controlled.

\section{Methods}

After approval by the Project Review and Human Studies Subcommittee of the VAMC Syracuse and after obtaining informed consent, 23 men scheduled for TURP were randomly assigned to a "low" block group or a "standard" block group. Randomization was achieved using the last digit of the patient's social security number. Patients with an even last digit were assigned to the control ("standard" block) group and patients with odd last digits were assigned to the "low" block group. It was assumed that the last digit had an equal chance of being either odd or even.

In the "low" block group, the goal was to provide an $\mathrm{L}_{3}$ or lower block level to pinprick; in the "standard" block group, the goal was to provide a block to $T_{10}$ or higher. An 18-gauge or larger intravenous catheter was inserted in all patients before block placement and 500 $\mathrm{ml}$ isotonic crystalloid were given to each patient before performing the spinal block. No pre-medication was given.

The "low" block patients $(n=13)$ received one milliter spinal bupivacaine $0.75 \%$ in dextrose $8.5 \%$ intrathecally through a 20-gauge Quincke tip needle placed through the $\mathrm{L}_{3-4}$ interspace with the patient in a sitting position. These patients remained in the sitting position for $20 \mathrm{~min}$ before being placed supine. In the "low" block patients, a 24-gauge polyamide subarachnoid catheter (Burron Medical Inc., Bethlehem, PA) was inserted after injection of the local anaesthetic. The spinal catheter was inserted to provide supplemental local anaesthetic as indicated.

"Standard" block patients $(n=10)$ received one and a half milliliters of the hyperbaric bupivacaine solution injected through a 22-gauge Quincke tip needle placed at the same interspace. A spinal catheter was not inserted and the patients were placed supine immediately after subarachnoid injection.

The dermatomal level of the block to pinprick was determined in all patients using a standard dermatomal chart. ${ }^{3}$ The block level was defined as the highest dermatomal segment with decreased sensation to pinprick. The block level and the systolic and diastolic blood pressure were recorded every five minutes for $20 \mathrm{~min}$ after injection. The patient was then transported to the op- erating room. Blood pressure, block level, bladder pressure, and VAPS were determined every five minutes throughout the procedure and any time the patient's pain abruptly increased. The VAPS was monitored using a straight, unruled ten centimeter line with one end labeled "no pain" and the opposite end labeled "worst pain imaginable." The patient was asked to indicate the point which best described the level of pain experienced. The score was determined by rounding to the nearest distance in centimeters from the "no pain" end.

The surgeon introduced the suction resectoscope, and, after moderate bladder distension, inserted a 20-gauge catheter into the bladder via a suprapubic approach using an epidural needle/catheter kit (Burron Medical Inc., Bethlehem, PA). The "low" block patients received suprapubic subcutaneous lidocaine $1 \%$ infiltration prior to catheter insertion. The catheter was connected to a standard calibrated transducer system (Viggo-Spectramed, Oxnard, CA) and the transducer was connected to a monitor (SpaceLabs, Inc., Redmond, WA). After zeroing the monitor to atmospheric pressure and adjusting the transducer height to read zero when the bladder was completely drained, a continuous display of real-time bladder pressure was obtained. Bladder pressure was monitored throughout the procedure and the surgeons were informed if bladder pressure exceeded $15 \mathrm{mmHg}$. An effort was made to keep the pressure below $15 \mathrm{mmHg}$ at all times during the procedure. Periodic adjustments, made by the surgeon when necessary, promptly lowered excessive bladder pressure.

An "inadequate block" was defined as a VAPS $\geq 5$ / 10 associated with prostatic resection (not bladder distension). For example, if pain $>5 / 10$ on the VAPS persisted during resection when bladder pressure was $<15$ $\mathrm{mmHg}$, then the block was considered inadequate. Forty milligrams lidocaine $2 \%$ (isobaric) were injected through the spinal catheter. When a cephalad extension of the original block was confirmed by pinprick, the procedure was resumed.

Midazolam (total dose $\leq$ two milligrams) was given in $0.5 \mathrm{mg}$ increments as indicated for anxiolysis. No other analgesics, sedatives, or anxiolytics were given during the intraoperative period.

After the procedure was complete, the total volume of glycine irrigant used, the mass of prostatic tissue resected (estimated by the same surgeon (IN) after each case), the duration of resection, the total midazolam dose administered, the total volume of iv fluids given, and the greatest change in systolic and diastolic blood pressure following block placement were recorded. For each patient, the mean VAPS and mean bladder pressure was calculated from all the values recorded throughout the case. The mean VAPS was not calculated in the "low" 
TABLE Summary of the variables for each group (mean \pm SD)

\begin{tabular}{lccc}
\hline & $\begin{array}{l}\text { "Low" block } \\
\text { group } \\
\left(\leq L_{3}\right) \\
(n=13)\end{array}$ & $\begin{array}{l}\text { "Intermediate" } \\
\text { block group } \\
\left(T_{12} \text { or } L\right) \\
(n=5)\end{array}$ & $\begin{array}{l}\text { "Standard" } \\
\text { block group } \\
\left(\geq T_{10}\right) \\
(n=5)\end{array}$ \\
Variable & $70 \pm 5$ & $71 \pm 4$ & $70 \pm 3$ \\
\hline Age & $82 \pm 11$ & $84 \pm 11$ & $82 \pm 4$ \\
Weight (kg) & $174 \pm 5$ & $177 \pm 4$ & $176 \pm 5$ \\
Height (cm) & $62.1 \pm 21.6$ & $54.8 \pm 23.0$ & $45.8 \pm 18.9$ \\
Duration of prostatic resection (min) & $21.8 \pm 8.2$ & $20.1 \pm 9.3$ & $16.2 \pm 4.2$ \\
Volume of irrigant (L) & $25.2 \pm 13.0$ & $23.0 \pm 15.7$ & $13.5 \pm 6.0$ \\
Mass of prostatic tissue resected (g) & $873 \pm 223$ & $740 \pm 207$ & $840 \pm 139$ \\
iv fluid & $1.5 \pm 0.7$ & $0.9 \pm 0.7$ & $0.9 \pm 0.8$ \\
Midazolam given (mg) & $2.8 \pm 1.4 * \dagger$ & $1.7 \pm 1.1$ & $0.2 \pm 0.4 \dagger$ \\
Visual analogue pain score (VAPS) & $12.4 \pm 8.3$ & $9.9 \pm 1.6$ & $12.3 \pm 8.7$ \\
Bladder pressure (mmHg) & $9 \pm 6$ & $14 \pm 8$ & $15 \pm 6$ \\
\% decrease in systolic BP & $8 \pm 7 \ddagger$ & $17 \pm 13 \ddagger$ & $20 \pm 6 \ddagger$ \\
\% decrease in diastolic BP & &
\end{tabular}

* $(n=8)$; the five "low" block patients who found their block inadequate were not included in this calculation. $\dagger(P<0.01)$; "low" vs "standard" block group using ANOV and Tukey's procedure for multiple comparisons. $\ddagger(P<0.025)$; "low" vs "standard" block group and "low" vs "intermediate" block group using ANOV.

block patients who found their block inadequate (see Table).

In five of the patients in whom a "standard" block was attempted, the block level was $\mathrm{T}_{12}$ or $\mathrm{L}_{1}$. These patients were retrospectively assigned to a third separate group called "intermediate" block group.

The variables collected for each group were summarized and compared between the groups using repeated measures analysis of variance and Tukey's procedure for multiple comparisons. The ratio of adequate versus inadequate blocks for each group was compared using the Chi square test and Fisher's exact test for small samples.

\section{Results}

We found no differences among the groups with respect to age, height, weight, duration of the resection, volume of glycine irrigant used, prostatic mass resected, mean bladder pressure during resection, total $i v$ fluids given, total iv midazolam dose given, and maximum decrease in systolic blood pressure after spinal block (Table) $(P$ $<0.05$ ).

No indications of an 'inadequate block' were found in either the "intermediate " block group $(n=5)$ or the "standard" block group $(n=5)$. There were no indications of an "inadequate block" in eight of 13 "low" block patients (62\%). In "low" block patients who found the block adequate $(n=8)$, the mean VAPS was greater $(P<0.05)$ than that of the "standard" block group (Table). In five of $13(38 \%)$ "low" block patients, the block was inadequate and required supplementation. In each of these patients, the block level was extended to the $L_{1}$ level using isobaric lidocaine injected through an indwelling spinal catheter. The new level was subsequently ade- quate for TURP. These patients were not assigned retrospectively to the "intermediate" block group for statistical analysis of block adequacy.

After the cystoscope was inserted, the bladder was moderately distended to facilitate insertion of the suprapubic intravesical catheter. We observed a VAPS $>5 /$ 10 in 12 of 13 "low" block patients (92\%) and 4/5 "intermediate" block patients $(80 \%)$ when bladder pressure was $>15 \mathrm{mmHg}$. However, when bladder pressure was decreased to $<15 \mathrm{mmHg}$, the VAPS rapidly and reproducibly decreased to $<5 / 10$. "Standand" block patients did not experience discomfort when the bladder distension pressure was $>15 \mathrm{mmHg}$. In addition, in "low" block patients, the VAPS increased when the surgeons acutely angled the resectoscope in the sagittal plane in an attempt to visualize posterior intravesical structures (such as the ureteral orifices). Discomfort was not noted in "intermediate" and "standard" block patients during similar manoeuvres.

The mean maximal percent decrease in systolic BP after spinal injection was $10 \%$ in the "low" block group, $15 \%$ in the "intermediate" block group, and $16 \%$ in the "standard" block group. The mean maximal percent decrease in diastolic BP was $8 \%$ in the "low" block group, $17 \%$ in the "intermediate" group, and $20 \%$ in the "standard" block group. By analysis of variance, the mean maximal percent decrease in systolic BP was not different $(P<0.05)$ among the groups, but the mean maximal percent decrease in diastolic BP was less in the "low" block group than in either the "intermediate" or "standard" block group $(P<0.05)$.

After extending the spinal block to the $\mathrm{L}_{1}$ level in "low" block patients who found their block inadequate $(n=$ 
5), the mean maximal percent decrease in SBP was $15 \%$ and the mean maximal percent decrease in diastolic BP was $14 \%$. The decreases in systolic and diastolic BP were similar $(P<0.05)$ to the decreases observed in the "intermediate" block group after spinal injection.

\section{Discussion}

In this study, no patient who had a spinal-block level $\geq \mathrm{L}_{1}$ found the block "inadequate"(VAPS $>5 / 10$ ) during TURP. Thirty-eight percent of patients with a block level $\leq L_{3}$ found the block inadequate. In the "low" block patients who found the block inadequate, the mid-lumbar block could be extended by administering lidocaine 40 $\mathrm{mg}$ (isobaric) through an indwelling spinal catheter. After the supplemental dose, the block level was extended to $L_{\text {I }}$ in each patient. Each patient subsequently found this level adequate for TURP.

In "low" block patients who found the block adequate, the VAPS was higher than in the "standard" block group. Despite "adequate" anaesthesia during TURP, "low" block patients found the block less complete than the "standard" block patients. The VAPS was similar between the "intermediate" and "standard" block groups.

There is little information in anatomy or anaesthesia textbooks to identify precisely the afferent innervation of the bladder and prostate. We did, however, find information which may explain why a mid-lumber level provided less complete anaesthesia than a block level $\geq \mathrm{L}_{1}{ }^{2,5}$ A sclerotome is the area of bone innervated predominantly by a single spinal segment, whereas a dermatome is the cutaneous area innervated by a single pair of sensory roots and their ganglia. ${ }^{6}$ Dubuisson ${ }^{7}$ notes that, "the pattern of innervation of the muscles and deep structures does not conform strictly to the overlying dermatomes." Deep segmental innervation supplied by the cervicothoracic and lumbosacral roots is often confined to the torso, whereas the corresponding dermatomal innervation extends down the arm or leg. ${ }^{7}$ Accordingly, the deep segmental innervation of the pubic arch is supplied by lumbar nerve roots 2,3 , and $4^{8}$ (see homunculus), while the corresponding dermatomal innervation from these roots extends down the leg distal to the knee. The prostate is closely related anatomically to this internal surface of the pubic arch (especially when the gland is hypertrophic). Heat induced by the cutting loop of the resectoscope during TURP may elicit pain, conveyed via the obturator nerve.

Moreover, the skin of the perineum, the voluntary musculature of the urogenital diaphragm, the perineal membrane (the inferior fascia of the urogenital diaphragm), the ischium and its tuberosity, and the medial aspect of the ilium are innervated by sacral roots. A spinal level $\leq L_{3}$ would be expected to block the nerves supplying these structures. However, the perineal membrane attaches to the deep pubic arch anteriorly and laterally. Acute angulation of the resectoscope in the sagittal plane would stretch the perineal membrane at its anterior attachment to the deep pubic arch (a bony area supplied by the lumbar plexus $\mathrm{L}_{2}-\mathrm{L}_{4}$ ). This may explain our observation that, in "low" block patients, the VAPS increased when the surgeons attempted to visualize posterior intravesical structures.

In his study, Evans found "complete analgesia ... in all cases where the upper level of the block reached the third lumbar segment." Therefore, it appears that Evans observed a higher adequacy rate for $L_{3}$ level sensory blocks (epidural or subarachnoid) than we observed in our subarachnoid block study. However, comparison of this study and Evans' study is of limited value. First, Evans' study did not use objective measures of pain or clearly define an "inadequate block" prospectively. Second, although Evans states "no supplementation was required, other than for the relief of apprehension [diazepam]", he did not record or limit the doses. Finally, the extent of the resection (mass of prostatic tissue resected) was not quantified and compared.

The Iglesias ${ }^{9}$ continuous flow suction resectoscope provides a clear operative field without irrigant accumulation within the bladder and its associated high intravesical pressure. Low pressure bladder irrigation during TURP has been shown to reduce intravascular irrigant uptake and may decrease the incidence and severity of "TURP" syndrome." ${ }^{10}$ If bladder pressure exceeds $15 \mathrm{mmHg}$ during TURP with the continuous flow suction resectoscope, bladder pressure may be lowered either by increasing the force of suction applied to the outflow channel or by decreasing the gravitational force applied to the irrigant.

In our study, bladder pressure was monitored using a dedicated percutaneous suprapubic 20 -gauge catheter. We chose not to monitor bladder pressure at the proximal inflow channel of the resectoscope during TURP. The pressure at this site would be higher than actual bladder pressure because flow through the inflow channel would generate a pressure gradient between its proximal and distal ends. Suprapubic catheter insertion is a common urologic procedure with a low associated morbidity. " Some urologists recommend inserting a \#16 French suprapubic trocar to monitor bladder pressure and to aspirate irrigant and prostatic tissue continuously during TURP. ${ }^{12}$ Mosegaard et al. found that this technique maintained a low intravesical pressure by closely matching irrigant outflow to inflow. ${ }^{13}$

Sympathetic efferent blockade results in a reduction in both cardiac preload and afterload. ${ }^{14}$ As might be expected, we found that the maximal percent decrease in diastolic BP in the "low" block group was less than that 
of the "standard" and "intermediate" block groups, but the maximum percent decrease in systolic BP was not different between the groups. Our data does not determine whether the observed decreases in diastolic BP resulted from a decrease in cardiac output or a decrease in systemic vascular resistance. The $500 \mathrm{ml}$ bolus of isotonic crystalloid given to each patient before spinal block placement may have minimized the BP decreases observed in all groups.

The maximal percent decrease in systolic and diastolic BP after extending the inadequate "low" block to $L_{1}$ were similar to the BP decreases observed in the "intermediate" block group. Therefore, given the same block level is ultimately achieved, the haemodynamic effects after supplementation of a "low" block were similar to those observed after a single shot technique.

In the population studied, the difference between a mean maximum decrease in diastolic blood pressure of 17 to $20 \%$ and an $8 \%$ decrease may not be clinically important. However, some TURP patients with severe cardiac dysfunction (e.g., critical aortic stenosis or poor left ventricular function) lack the physiological reserve necessary to compensate for even minor changes in sympathetic tone. In these patients, the percent decreases in diastolic blood pressure which were observed in this study may carry more clinical importance.

Patients with severely limited pulmonary reserve may also benefit from limiting the cephalad distribution of spinal block. Spinal block levels at or above $T_{10}$ impair forced expiratory flow rates. ${ }^{15}$ Spinal block above $T_{10}$ jeopardizes patients with excessive sputum production (e.g., chronic bronchitics or heavy smokers) because these patients are unable to clear their secretions effectively. ${ }^{16}$ Our study suggests that a $T_{12}$ or $L_{1}$ spinal block level is adequate for TURP; data in the literature suggests that a block level $<\mathrm{T}_{10}$ may avoid adverse pulmonary effects. Perhaps a $T_{12}$ or $L_{1}$ block level may be a reasonable compromise between avoiding the adverse pulmonary effects of a "standard" block while avoiding a "less complete" anaesthetic with a "low" block. Further studies are required to determine if a $T_{12}$ or $L_{1}$ block level is the best choice for the "pulmonary cripple."

If the patient rated his pain greater than $5 / 10$ during prostatic resection, the patient was determined to have an "inadequate block." Some clinicians may consider this threshold too high. Furthermore, a $62 \%$ success rate in "low" block patients may be unacceptable to patients and clinicians, even with ready access to a subarachnoid catheter. Our goal was to "test the limits" without unreasonable extremes. One must weigh the risk of providing a "less adequate" or "inadequate" block if a "low" block is planned. In patients with severely limited cardiac and pulmonary reserve, the benefits of avoiding partial sym- pathectomy may outweigh these risks. Our study population did not include severely compromised patients, so our results may not apply to this patient population.

Our results suggest that if a "low" block is planned for TURP, a spinal catheter should be inserted prospectively for supplementation as indicated. The use of microspinal catheters has been associated with cauda equina syndrome. ${ }^{17}$ Currently, the thinnest spinal catheter available for clinical use in the United States is a 24-gauge polyamide catheter, which requires a 20-gauge spinal needle for its insertion. Alternatively, a combined epidural/ spinal technique may bring together the advantage of a subarachnoid block and the flexibility of continuous epidural access. The combined technique has been used to extend a subarachnoid block during Caesarean section; ${ }^{18}$ the combined technique may provide an alternative means to "bail out" an inadequate "low" block.

Opioids added to intrathecal local anaesthetics reduce the incidence of lower extremity tourniquet pain. ${ }^{19}$ Adding opioids to epidural local anaesthetics has been shown to alleviate visceral discomfort during Caesarean section. ${ }^{20}$ By increasing the spread or intensity of the subarachnoid block, intrathecal adjuvants (e.g., opioids such as fentanyl) might have improved the adequacy rate of the "low" block. Supplemental intravenous analgesics (opioids or ketamine) might also have improved the adequacy rate. Nonetheless, neither of these hypotheses are supported by our data.

In conclusion, we have shown that a subarachnoid block $\geq \mathrm{L}_{1}$ provided adequate analgesia during TURP in our patient sample. A level $\leq L_{3}$ was adequate in $62 \%$ of patients. If the "low" block level was inadequate during prostatic resection, the block could be extended using a spinal catheter. Since bladder distension elicited pain under a "low" or "intermediate" block, monitoring and controlling bladder pressure during TURP are suggested for block levels $<T_{10}$.

\section{Acknowledgments}

The authors gratefully acknowledge Dr. Richard Oates for the statistical analysis of our data and Patricia Boutis for the preparation of the manuscript.

\section{References}

1 Raj PP, Gesund P, Phero J, et al. Rational choice for surgical procedures. In: Raj PP (Ed.). Clinical Practice of Regional Anesthesia. New York: Churchill-Livingstone, 1991: 231.

2 Evans TI. Regional anaesthesia for transurethral resection of the prostate - which method and which segments? Anaesth Intensive Care 1974; 2: 240-2.

3 Barash PG, Cullen BF, Stoelting RK. Clinical Anesthesia. Philadelphia: J.B. Lippincott, 1989: 760. 
4 Jamison $R N$. Clinical measurement of pain. In: Ferrante FM, VadeBoncouer TR (Eds.). Postoperative Pain Management. New York: Churchill Livingstone, 1993: 121.

5 Tulli $G$, Barberio $O$, De Gregori $P D$, et al. L'analgesia spinale medio-lombare nella resezione transuretrale della prostata. Minerva Anestesiol 1983; 49: 233-40.

6 Bonica JJ. The Management of Pain, 2nd ed. Philadelphia: Lea \& Febiger, 1990: 133.

7 Dubuisson $D$. Nerve root damage and arachnoiditis. In: Wall PD, Melzack R (Eds.). Textbook of Pain, 3rd ed. Edinburgh: Churchill Livingstone, 1994: 711-3.

8 Bonica JJ. The Management of Pain, 2nd ed. Philadelphia: Lea \& Febiger, 1990: 141.

9 Iglesias JJ, Sporer A, Gellman AC, Seebode JJ. New Iglesias resectoscope with continuous irrigation, simultaneous suction and low intravesical pressure. J Urol 1975; 114 : 929-33.

$10 \mathrm{Hahn} R G$. The transurethral resection syndrome. Acta Anaesthesiol Scand 1991; 35: 557-67.

11 Thuroff JW. Retrograde instrumentation of the urinary tract. In: Tanagho EA, McAninch (Eds.). Smith's General Urology, 12th ed. Norwalk, CT. Appleton and Lange, 1988: 164.

12 Reuter HJ, Jones LW. Physiologic low pressure irrigation for transurethral resection: suprapubic trocar drainage. J Urol 1974; 111: 210-2.

13 Mosegaard A, Madsen PO. Trocar cystostomy during transurethral prostatic resection. Urology 1974; 3: 735-40.

14 Greene NM, Brull SJ. Physiology of Spinal Anesthesia. 4th ed. Baltimore: Williams \& Wilkins, 1993: 149-63.

15 Paskin S, Rodman T, Smith TC. The effect of spinal anesthesia on the pulmonary function of patients with chronic obstructive pulmonary disease. Ann Surg 1969; 169: 35-41.

16 Aldrete $J A$, Woodward ST, Turk $L H$. Influence of cigarette smoking on the changes produced by spinal anesthesia on expiratory forced volumes and flow rates. Anesth Analg 1973; 52: 809-15.

17 Lambert $D H$, Hurley RJ. Cauda equina syndrome after continuous spinal anesthesia. Anesth Analg 1991; 72: 817-9.

18 Rawal N, Schollin J, Wesström G. Epidural versus combined spinal epidural block for cesarian section. Acta Anaesth Scand 1988; 32: 61-6.

19 Tuominen $M$, Valli $H$, Kalso E, Rosenberg PH. Efficacy of $0.3 \mathrm{mg}$ morphine intrathecally in preventing tourniquet pain during spinal anaesthesia with hyperbaric bupivacaine. Acta Anaesth Scand 1988; 32: 113-6.

20 Gaffud MP, Bansal P, Lawton C, Velasquez N, Watson $W A$. Surgical analgesia for cesarian delivery with epidural bupivacaine and fentanyl. Anesthesiology 1986; 65: 331-4. 